ఠ

CASE REPORT

\title{
Adaptive optics assisted visualization of thickened retinal arterial wall in a patient with controlled malignant hypertension
}

This article was published in the following Dove Press journal:

Clinical Ophthalmology

6 October 2014

Number of times this article has been viewed

\author{
Shigeta Arichika \\ Akihito Uji \\ Nagahisa Yoshimura \\ Department of Ophthalmology \\ and Visual Sciences, Graduate School \\ of Medicine, Kyoto University, \\ Kyoto, Japan
}

Purpose: We aimed to visualize the retinal arterial wall thickness, assisted by noninvasive adaptive optics scanning laser ophthalmoscopy (AO-SLO).

Methods: The arterial wall thickness was measured and compared between one normal subject and one patient suffering from malignant hypertensive retinopathy.

Results: Increased arterial wall thickness was revealed with a newly developed AO-SLO system, in a retinal artery of 1-papilla diameter temporal inferior to the optic disc. The average wall thickness, with hypertension, was $18.7 \mu \mathrm{m}$, and the wall-to-lumen ratio was 0.44 , both bigger than normal.

Conclusion: AO-SLO enabled us to evaluate the retinal wall thickness in the hypertensive patient. The arterial walls were thickened compared with normal. AO-SLO may facilitate future noninvasive study of arterial walls in human medicine.

Keywords: wall thickness, AO-SLO, hypertensive retinopathy

\section{Introduction}

The Keith-Wagener ${ }^{1}$ and Scheie $^{2}$ classification schemes are widely used for staging of hypertensive and arteriosclerotic changes, by categorizing vascular appearance on ophthalmoscopic examination or color fundus photography. Recently, direct visualization of the arterial walls in the retina using adaptive optics scanning laser ophthalmoscopy (AO-SLO) has been reported and is expected to provide valuable information on hypertensive and sclerotic arterial changes. Herein, we illustrate a case of malignant hypertension in which AO-SLO images clearly demonstrated a thickened retinal arterial wall.

\section{Case report}

A 33-year-old woman complaining of decreased vision in the right eye was referred to our institution. Her visual acuity was 20/50 in the right eye and 20/20 in the left eye. Fundus examination revealed retinal hemorrhage, "cotton-wool" spots, and papilledema in both eyes, with macular edema in the right eye (Figure 1). Spectral-domain optical coherence tomography (SD-OCT) (Spectralis ${ }^{\circledR}$; Heidelberg Engineering, Heidelberg, Germany) showed serous retinal detachment and hyperreflective foci, which represented precursors of hard exudate in the retina. Her blood pressure was $234 / 134 \mathrm{mmHg}$, and blood tests showed elevated serum creatinine level (14 mg/dL). Moreover, abdominal magnetic resonance imaging (MRI) revealed bilateral renal atrophy. She was diagnosed with malignant nephrosclerosis, malignant hypertension, and hypertensive retinopathy. Hemodialysis and antihypertensive treatment
Correspondence: Akihito Uji

Department of Ophthalmology

and Visual Sciences, Kyoto University

Graduate School of Medicine,

54 Kawahara-cho Shogoin, Sakyo-ku,

Kyoto 606-8507, Japan

Tel +81757513248

$\mathrm{Fax}+8 \mathrm{I} 757520933$

Email akihitol@kuhp.kyoto-u.ac.jp 

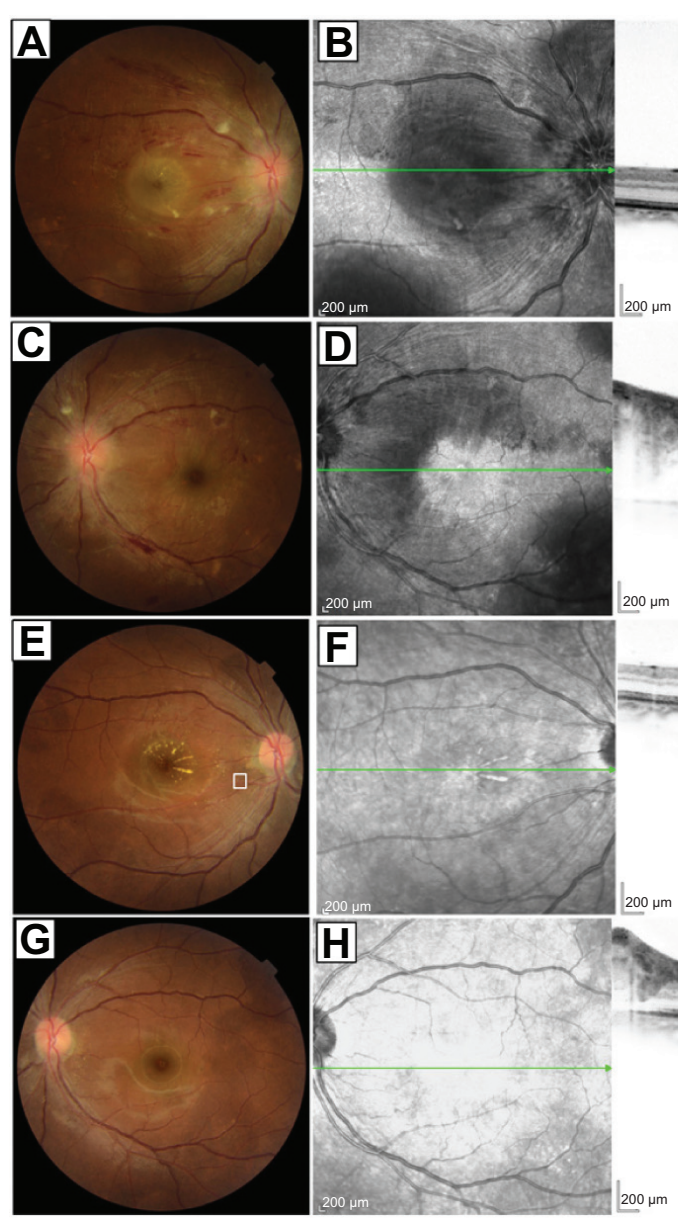

Figure I Fundus photographs and spectral-domain optical coherence tomography (SD-OCT) before and after treatment.

Notes: Images of both eyes of a 33-year-old woman with hypertensive retinopathy (A-D) before treatment and (E-H) 3 months after hypertensive treatment started. (A) Color photograph of the right eye shows retinal hemorrhage, "cotton-wool" spots, papilledema, and macular edema. (B) Horizontal line scan on SD-OCT of the right eye shows serous retinal detachment and hyperreflective foci, representing precursors of hard exudate in the retina. (C) Color photograph of the left eye shows retinal hemorrhage, cotton-wool spots, and papilledema, all of which are milder than those in the right eye. (D) Horizontal line scan on SD-OCT of the left eye shows serous retinal detachment and hyperreflective foci. (E and $\mathbf{G}$ ) Fundus findings reveal favorable response to hypertensive treatment. (F and $\mathbf{H})$ Horizontal line scans on SD-OCT of both eyes show complete disappearance of serous retinal detachment. The scale bar represents $200 \mu \mathrm{m}$. Green arrows represent the sectioned line of the SD-OCT.

were started immediately. Three months later, her blood pressure had decreased to 115/69, and abnormal findings, except for minimal deposition of hard exudate in the fundus, had resolved. Visual acuity in the right eye had improved to 20/16. Increased arterial wall thickness was revealed with an AO-SLO system (Canon Inc., Tokyo, Japan) in a retinal artery of 1-papilla diameter temporal inferior to the optic disc in the right eye (Figure 2). The average wall thickness was $18.7 \mu \mathrm{m}$, and the wall-to-lumen ratio was 0.44 .

\section{Adaptive optics scanning laser ophthalmoscopy}

We developed a novel AO-SLO system with a high wavefront correction efficiency, using a dual liquid-crystal phase modulator (LCOS-SLM, model X10468-02; Hamamatsu Photonics, Hamamatsu City, Japan). The AO-SLO videos were acquired at 32 frames/second in an area covering the parafovea. The scan area was $2.8^{\circ} \times 2.8^{\circ}$ at the retina, with a sampling of $400 \times 400$ pixels. All AO-SLO imaging was performed with the optical focus adjusting on the vessel wall to be described clearly.

\section{Discussion}

AO-SLO is a useful modality for noninvasive demonstration of, not only photoreceptor cells, but also, blood flow, blood corpuscles, and the retinal nerve fiber layer. Recently, visualization of arterial wall thickness in the retina has been reported. ${ }^{3}$ In the current report, AO-SLO yielded clear images of a vascular wall in a patient with controlled malignant hypertension and revealed thickening of the vessel wall compared with a normal volunteer of the same age as the patient. The wall-to-lumen ratio reported here concurred with previous 


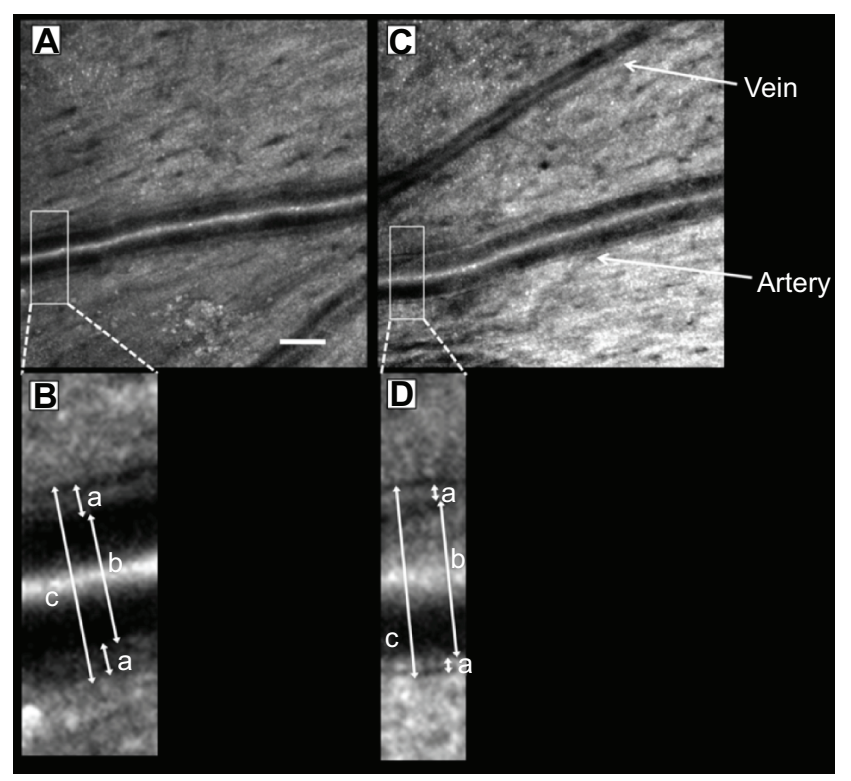

Figure 2 Adaptive optics scanning laser ophthalmoscopy (AO-SLO) images of thickened retinal arterial wall.

Notes: (A) AO-SLO image, corresponding to the area outlined in white in Figure $\mathrm{IE}$, of a retinal artery in controlled hypertensive retinopathy and $(\mathbf{B})$ magnified image of the area outlined in white in (A). (C) AO-SLO image of a retinal artery temporal-superior to the optic disc in a normal subject and (D) magnified image of the area outlined in white in (C). (A) Scale bar $=100 \mu \mathrm{m}$. (B) The arterial wall (a) is thicker than that of the normal subject in (D). The average wall thickness (a), inner diameter (b), outer diameter (c), and wall-to-lumen ratio of the retinal artery were $18.7 \mu \mathrm{m}, 86.2 \mu \mathrm{m}, 123.7 \mu \mathrm{m}$, and 0.44 , respectively. (D) The average wall thickness (a), inner diameter (b), outer diameter (c), and wall-to-lumen ratio of the retinal artery were $10.7 \mu \mathrm{m}, 92.4 \mu \mathrm{m}, \mathrm{I} 13.7 \mu \mathrm{m}$, and 0.23 , respectively.

results obtained using Doppler flowmetry by Ritt et $\mathrm{al}^{4}$ and Rizzoni et $\mathrm{l}^{5}$ who reported wall-to-lumen ratios of 0.28 and 0.26 , respectively, for normotensive subjects, and of 0.36 and 0.37 , respectively, for hypertensive patients. The changes in arterial structure in hypertension are considered to result from mechanoadaptive processes to maintain optimum levels of wall tension or stress. Although blood pressure was well controlled in this patient, the arterial wall thickening suggested that blood vessel wall changes were irreversible to a certain extent. AO-SLO may facilitate future noninvasive study of arterial walls, in human medicine. In the near future, we intend to conduct further studies using an appropriate number of patients.

\section{Acknowledgment}

This work was supported in part by the Innovative TechnoHub for Integrated Medical Bio-imaging Project of the Special Coordination Funds for Promoting Science and Technology, from the Ministry of Education, Culture, Sports, Science and Technology, Japan.

\section{Disclosure}

Nagahisa Yoshimura received lecture fees and research funding from Canon. The authors report no other conflicts of interest in this work.

\section{References}

1. Keith NM, Wagener HP, Barker NW. Some different types of essential hypertension: their course and prognosis. Am J Med Sci. 1974;268(6): 336-345.

2. Scheie HG. Evaluation of ophthalmoscopic changes of hypertension and arteriolar sclerosis. AMA Arch Ophthalmol. 1953;49(2):117-138.

3. Chui TY, Vannasdale DA, Burns SA. The use of forward scatter to improve retinal vascular imaging with an adaptive optics scanning laser ophthalmoscope. Biomed Opt Express. 2012;3(10):2537-2549.

4. Ritt M, Harazny JM, Ott C, et al. Analysis of retinal arteriolar structure in never-treated patients with essential hypertension. J Hypertens. 2008 26(7):1427-1434

5. Rizzoni D, Porteri E, Duse S, et al. Relationship between media-to-lumen ratio of subcutaneous small arteries and wall-to-lumen ratio of retinal arterioles evaluated noninvasively by scanning laser doppler flowmetry. J Hypertens. 2012;30(6):1169-1175.
Clinical Ophthalmology

\section{Publish your work in this journal}

Clinical Ophthalmology is an international, peer-reviewed journal covering all subspecialties within ophthalmology. Key topics include: Optometry; Visual science; Pharmacology and drug therapy in eye diseases; Basic Sciences; Primary and Secondary eye care; Patien Safety and Quality of Care Improvements. This journal is indexed on

\section{Dovepress}

PubMed Central and CAS, and is the official journal of The Society of Clinical Ophthalmology (SCO). The manuscript management system is completely online and includes a very quick and fair peer-review system, which is all easy to use. Visit http://www.dovepress.com/ testimonials.php to read real quotes from published authors. 